\title{
Prejubilaciones y segunda oportunidad: Algunas consecuencias del nuevo mercado de trabajo
}

JOAQUíN ZAMORANO

Facultad de CC. Económicas Universidad Complutense. Madrid

A Luis Miguel Sevillano

Una anécdota pocas veces debería justificar un argumento. Pero, cuando se da tal cantidad, referidas a un mismo tema, se exige un argumento que sirva para referenciar y analizar dichas anécdotas. Viene esto a cuento de las condiciones de trabajo que se han generado en un sector muy significativo de nuestra sociedad, como es el de los jóvenes universitarios con educación adicional a la licenciatura; es decir, prácticamente todos los licenciados.

Uno de los cambios mayores y más relevantes que han ocurrido en España durante los últimos años es el que se refiere al esfuerzo realizado por sus jóvenes para obtener una mayor educación; o, más concretamente, la demanda de formación que dicho grupo de población ha venido llevando a cabo con la finalidad básica y muy especial de conseguir un puesto de trabajo interesante. Esa mayor formación se ha materializado en unos conocimientos de idiomas, maestrías y prácticas empresariales previas a su incorporación definitiva al mundo laboral muy extensos y comunes y que dotan a estos colectivos de una formación impensable para las otras generaciones, incluso las inmediatamente anteriores. Tal ha sido la magnitud de este cambio que el número de jóvenes que en estos momentos dispone de esta formación suficiente para trabajar en puestos interesantes supera ampliamente la capacidad del sistema para generar dichos puestos. Varias son las consecuencias de este desajuste, y su exposición y las reflexiones que suscita son el objeto del presente trabajo.

I

En primer lugar se asiste a una competencia horizontal -es decir, entre ellos mismos - muy fuerte, de forma que el salario ofrecido a estos "trimaster y trilingues" es tan reducido que resulta ofensivo para ellos, por 
no estar en consonancia con el esfuerzo realizado; pero también para los padres, por el coste de lo invertido, y para la propia sociedad, ante el derroche de recursos que supone. Por otra parte, como veremos más abajo, con esa formación no se eleva el nivel cultural de la sociedad (de modo que aunque terminen siendo, por ejemplo, dependientes, el resultado sea satisfactorio por tener un bagaje cultural más elevado), ya que tal formación tiene como finalidad exclusiva la mejora profesional. Es decir, si no están donde piensan que deberían estar por esfuerzo y sacrificio, la frustración anidará en ellos y pueden convertirse, con el tiempo, en una rémora importante para la sociedad.

Otra de las características de un mercado así es la velocidad de sustitución entre los trabajadores, propiciada por los avances tecnológicos, por la disponibilidad de nuevos candidatos para entrar en el grupo a cualquier precio y, obviamente, por los empleadores que prefieren una plantilla joven, tanto por representar un menor coste, como por indicar sintonía con los tiempos modernos que, desde cualquier aspecto - moda, medios de comunicación, criterios actuales de estética-, crean la sensación de que la eficiencia sólo se consigue con plantillas donde domina la juventud.

Se ha generado, por tanto, una sensación de vértigo que responde a la creencia de que, si no se está en movimiento, se está perdiendo algo: todos los elementos que configuran este mercado laboral responden a que hay que actuar continuamente deprisa, aunque no se vaya a ningún lado, ni se sepa dónde se va, ni para qué. Así las cosas, poco pueden hacer los propios trabajadores, salvo defender su puesto de trabajo a través, paradójicamente, de intensificar ese desarrollo. En circunstancias donde se identifica ruido con actividad, siempre hay otro "trimaster" potencialmente más preparado, dispuesto a trabajar por un sueldo menor y a aceptar unas condiciones de trabajo cada vez más leoninas. En definitiva, dispuesto a adentrarse y asumir el proceso de selección y estímulo que se le ofrece y que los anteriores ya probaron, aunque no consiguieron estabilizarse en él. Las consecuencias sociológicas y psicológicas son múltiples e importantes, pero escapan a los fines básicos de este artículo, más orientado a las condiciones del mercado de trabajo que se ha venido creando. Cabría, sin embargo, señalar algunas de ellas, porque inciden directamente en las formas de vida que se están generando.

Así, se constata la desaparición de ciertas acepciones que se conferían a la semana como espacio de tiempo para desarrollarse o vivir. Ahora sólo resta una acepción: la semana laboral. Las jornadas de trabajo se extienden de tal manera que dejan pequeña aquella expresión de "trabajar de sol a sol" que se utilizaba para definir términos de semiesclavitud 
y, a decir verdad, la mayoría de los trabajadores de estos sectores no ven la luz del sol durante una parte importante del año: salen del trabajo y se encaminan a casa, sin tiempo ni ganas para otras funciones que las estrictamente necesarias para la subsistencia y la mínima convivencia familiar. Todas aquellas actividades sociales o de formación no directamente vinculadas a la profesional, sencillamente han dejado de realizarse. Hasta el mismo fin de semana, antaño entendido de forma mayoritaria como ese espacio de tiempo concedido (conquistado) en el cual uno podría llevar la vida que realmente le gustaría llevar el resto de la semana, se ha convertido en un tiempo disponible para descansar y estar en perfecto estado para el trabajo de la semana siguiente.

Durante el resto de la semana la motivación básica es el deseo de que el sacrificio que se haga tenga una repercusión inmediata en el plano profesional. Además, en un día cualquiera resulta ya muy difícil trabajar y vivir, incluso entendiendo por esto su mínima expresión, es decir, aquel tiempo dedicado a lo que no es trabajar. Las ciudades comienzan a dar síntomas de declive. El silencio que reina en la actualidad a las diez $u$ once de la noche en estas ciudades es el que antaño se atribuía a las dos o tres de la madrugada. No se valora la situación; sólo se constata.

Otra de las características de esta demanda de formación es la carencia de una vocación de conocimiento, en el sentido de saber más y comprender mejor dentro de una forma de entender la vida. Según queda dicho, la demanda de formación tiene casi exclusivamente miras profesionales, para cuyo logro no se repara en esfuerzos; pero eso exige aunque sólo sea porque el tiempo es limitado- abandonar las restantes actividades a lo largo de los días laborables y buena parte del sábado y domingo. En esas circunstancias, las únicas fuentes de formación más accesibles, y acaso las únicas disponibles, son la televisión y los compañeros de trabajo. La primera, se sabe lo que da de sí; la segunda poco puede aportar en este sentido educador ya que, por definición, los compañeros de trabajo tienen un bagaje cultural y experimental muy parecido al de uno. Internet, en este sentido, parece que podrá tener un papel determinante, pero, por ahora, no deja de ser una posibilidad, y, dado el uso que hasta ahora se está haciendo, no invita a ser precisamente, en este aspecto, optimista. En definitiva, los individuos de ese colectivo se preparan para ganarse la vida con una exclusividad y una obsesión que, como tan claramente ha expuesto el profesor Lledó, «es la forma más fácil de malgastarla y no merece la pena vivir asín (El País, 30 de abril 1999).

La competencia o, más bien, la consciencia de que puede venir otro competidor que acepte mejor las condiciones que progresivamente se 
imponen, justifica, en última instancia, en estos jóvenes profesionales, unas jornadas laborales desmesuradas y a todas luces incompatibles con un desarrollo equilibrado de la persona en facetas distintas de las laborales. Las consecuencias fuera del ámbito laboral son apabullantes, en forma de frustración, depresiones, divorcios, ausencia en el proceso de crecimiento de los hijos... Los mejores de este proceso - los que más arduamente se han dedicado al trabajo y menos a otro tipo de desarrollos- son nombrados responsables, jefes. Se ponen, así, al frente de las plantillas unas personas que saben poco de ellas mismas, de sus sensaciones o de sus sentimientos, dada la falta de tiempo y de estímulo que les ha dejado la exigencia laboral requerida para llegar adonde han llegado. Forzando el argumento, se podría establecer que, precisamente, aquellas personas seleccionadas para los puestos de responsabilidad son las que menos oportunidades han dado a su formación personal, aunque sea solamente por esa falta de tiempo. Se las coloca ahí por sus conocimientos técnicos, pero con frecuencia presentan una inmadurez importante que les hace no conocerse a sí mismas, salvo en lo que se refiere a su determinación de estar dispuestas a trabajar con dedicación exclusiva. En estas circunstancias, resulta vacuo pedirles que sepan y comprendan las sensaciones o sentimientos ajenos, así como exigirles que intenten motivar al grupo de trabajo con formas ajenas a las de los incentivos contemplados por la empresa o que sepan relativizar prioridades y resolver los conflictos más allá de los cauces marcados por la organización empresarial y sus objetivos inmediatos.

El disponer de individuos que tengan este conocimiento de sí mismos, y deseo de volcarlo hacia los que trabajan con ellos, es esencial para toda corporación, sobre todo en épocas como la actual, en que la congelación salarial es manifiesta, dadas las reducidas tasas de inflación existentes, así como la precariedad de promociones internas, por la exigencia de reducir costes ante la competencia existente y que se fomenta con este esquema que se ha ido desarrollando; en épocas, en definitiva, en que hay que administrar la carestía y las limitaciones y en las que la motivación a través de la integración en equipos en los que sentirse a gusto y compensar otro tipo de retribución es esencial. Pero lo significativo desde este punto de vista es que el marco de selección está formado: o te adaptas a las exigencias del trabajo o no cuentes con que nadie vaya a comprenderte o a ayudarte. Quizás exista un punto de exageración en todo esto, pero no de falsedad.

La dilatada jornada laboral no sólo refleja un meritoriaje - por lo demás, digno y respetable ante la dureza del mercado laboral-; expone otro aspecto que caracteriza a los integrantes de este sector laboral y que 
es un magnífico ejemplo de cómo las prácticas del mercado laboral determinan la forma de vivir: mientras se permanece en el puesto de trabajo, además de mostrarse uno mismo a sus superiores, resulta que no se gasta dinero. Surge, pues, una forma de ahorrar que no viene inducida solamente por la escasez del salario percibido, como era corriente desde siempre, sino por otra motivación adicional que, además, constituye otra característica de estos colectivos, como es la de identificar diversión con gasto. El trabajo puede ser aburrido, agotador, exigente en horas de permanencia y en la capacidad de despersonalizar que supone, pero no parece que haya otra alternativa. Se permanece más de lo deseado, porque la estancia se valora a efectos de ascensos y de mantener el puesto de trabajo y, al mismo tiempo, se está ahorrando.

Cabe destacar también el elevado nivel de endogamia existente en esos grupos, caracterizado por los numerosos matrimonios formados por individuos de estas características. La falta de tiempo para realizar otro tipo de actividades (además del gimnasio que se realiza por estética y por liberación nerviosa) lleva a que la forma más normal $-\mathrm{y}$, acaso la úni$\mathrm{ca}$ - de conocer gente sea en el propio centro de trabajo. Esos matrimonios - en los que, en absoluto, tiene por qué presuponerse ausencia de amor- se configuran como una especie de núcleo defensivo ante las agresiones del mundo exterior, fundamentalmente del laboral. Los engaños también tienen su origen en ese ámbito.

Por eso, cuando un miembro de estos colectivos se convierte en parado, la desgracia de su nuevo status transciende el mero campo laboral. No es ya solamente que esa persona vea interrumpida su carrera profesional, que lo hace, que le sea más difícil encontrar trabajo con esta mácula, que lo es, sino que deja de ser persona desde el punto de vista del grupo de referencia que está emergiendo y al que pertenecía. Se le está expulsando del grupo, no sólo a efectos de laboriosidad y dignidad profesional, sino casi a todos los demás efectos (por ejemplo, ya no es el receptor y protagonista de toda la publicidad generada por los medios de comunicación en sentido amplio). Trabajar es tener dinero, lo cual se identifica con poder hacer cosas, mientras que sin él, uno se ve abocado a no hacer nada. Existen muchas diversiones gratuitas, pero este colectivo parece ser que apenas las valora: diversión -elemento que, a la postre, justifica esa existencia tan dura- es, para ellos, fundamentalmente, capacidad de gasto.

Otra contradicción de esta cosmología surge al exigir las empresas a los trabajadores una especial capacidad para trabajar en equipo, hasta el punto, según los anuncios al uso, de constituir un requisito poco menos que imprescindible (de hecho, se utiliza, al igual que los idiomas, para 
justificar una exclusión poco justificable). Una vez dispuestos a trabajar en equipo, los individuos han de percibir a sus colegas del grupo como sus más acérrimos rivales, siendo frecuente durante la incorporación de un trabajador la frase: "te presento a fulanito, vete enseñándole, que luego veremos qué hacemos contigon. Tremenda la posición del empleado más antiguo. Los sociólogos llaman a esa medida "descualificación". Nadie le ha quitado los conocimientos al empleado más antiguo; el miedo se deriva de una debilidad que siente por el mero paso del tiempo y la frecuencia de los ajustes de plantilla en la misma dirección. En fin, que parodiando aquella frase de "se hicieron a sí mismos", la contestación sería "pues se podían haber esmerado".

Pero las jornadas de "sol a sol" y la total disponibilidad no lo son todo. Se requiere además una identificación plena, sin fisuras ni críticas, con la empresa. La sociedad que estamos creando es más libre en el sentido de que ofrece más opciones y más diversas pero, al mismo tiempo, es mucho menos permisiva en el sentido de que los costes de ejercer alguna opción que no sea aceptada social y, sobre todo, empresarialmente, son muy elevados. Anteriormente, en todas las empresas había gente que trabajaba, que rendía, pero que no estaba de acuerdo con la empresa o con el jefe y así lo manifestaba. Ahora esa actitud no es posible. O se está conmigo (la empresa) o contra mí; trabajar exige no sólo disponer de todas las horas del trabajador, sino también de su conciencia.

La otra competencia que se da en estos mercados es la vertical; es decir, la aparición, acaso con toda razón, de una cierta predisposición contra aquél que estos jóvenes consideren que tiene un puesto de trabajo interesante y, por tanto, digno de ser ocupado por ellos mismos. Por trabajo interesante puede entenderse uno que sea estable (frente a la precariedad, que también se da en este segmento de la población trabajadora), que esté muy bien retribuido (sin tener en cuenta si se debe al factor antigüedad) $o$, en fin, que sea realmente interesante. No se trata, por ahora, de nada personal (¡menos mal!, cabría decir, recordando a Sánchez Ferlosio en este aspecto), sino más bien de un sentimiento hacia el colectivo de trabajadores estables que todavía no han terminado de definir. Ni qué decir tiene que si esta situación persiste y, por tanto, se agrava, ese sentimiento que es colectivo por ahora, podrá llegar a particularizarse; y no es descartable, en absoluto, llegar a asistir a verdaderas cazas de profesionales que pertenezcan a este grupo.

Tal situación tiene también repercusiones en la cúpula directiva de las empresas, en el sentido de generar una predisposición adicional en contra del segmento intermedio, por cuanto su permanencia en el centro de trabajo impide regenerar las ambiciones de mando tan necesarias para la 
empresa (y para los propios directivos, claro). Además, una estancia muy prolongada en un trabajo o puesto determinado comienza a no verse con agrado, porque, entre otras razones, no responde a los cánones de modernidad establecidos. En este ámbito, más cambios de trabajo es sinónimo de la intensidad con que se toma esa persona su vida profesional y la importancia que le asigna en su sistema de valores; la búsqueda de nuevas oportunidades de trabajo se considera como una especie de sano inconformismo ante un trabajo ya asimilado o que comienza a ser frustrante.

Por último, la presencia prolongada es molesta porque se teme que los conocimientos profesionales de quienes llevan mucho tiempo pueden llegar a ser muy parecidos a los de los altos mandos o, incluso, superiores si, como ocurre con frecuencia, las nuevas labores administrativas que los puestos elevados inevitablemente conllevan les consumen una buena parte de su tiempo, de modo que no pueden dedicarse al avance tecnológico. Finalmente, dicha estancia prolongada molesta porque constituye una referencia continua al proceso de ascenso de los propios jefes y a las vicisitudes que tuvieron que afrontar, las cuales, con demasiada frecuencia, no son siempre dignas de ser recordadas, sino condenadas.

En el caso de la empresa privada, además, se produce otra predisposición desfavorable frente a este colectivo derivada del convencimiento de que los jóvenes formados lo pueden hacer mejor y, sobre todo, más barato. Obviamente, esta tensión entre colectivos nuevos y antiguos de trabajadores siempre ha existido, con mayor o menor intensidad, en todas las épocas y en todos los sectores, y se consideraba a los mayores por su experiencia del negocio; por eso, a partir de los 50 años se encontraba la recompensa profesional. Pero ahora la diferencia es que, además del desfase de formación existente a favor de los jóvenes y de su mayor adaptación a un mundo cambiante, el activo mayor de los antiguos, como es la experiencia, vale bien poco porque el marco actual no tiene nada que ver con el de apenas hace unos años. Las nuevas habilidades complejas ya no son aditivas, de las que permiten construir siempre más alto sobre los mismos cimientos. Parece que el desarrollo de nuevos campos requiere un enfoque desde el comienzo, una aproximación que los jóvenes realizan con mayor eficacia.

Además, la experiencia que pueden presentar tiene poco valor de uso si no son capaces de integrarse en la red informática del centro de trabajo y en la organización a la que pertenece. Nótese que no es la referencia a las diferentes formas de asimilación que cada uno de los grupos tiene de los conocimientos informáticos, sino que ese conocimiento exclusivo y muy difícil de transmitir que es la experiencia (y que ha veni- 
do constituyendo el patrimonio de los antiguos para defenderse de los embates modernos) vale de bien poco si no se incorpora al sistema informático de la empresa, a sus programas. Así, la última barrera tradicional de defensa de los antiguos se ha derrumbado, como las murallas de Jericó, aunque en esta ocasión no sea, precisamente, atribuible a la música.

Cabe reconocer en descargo de este colectivo que ellos no crearon ese marco laboral y de relaciones; se lo encontraron hecho y no tuvieron participación alguna. Pero, lo preocupante es que, precisamente por no ser de su responsabilidad el verse totalmente inmersos en ese marco y, sin embargo, sufrir sus consecuencias, no presenten ninguna intención de rebelarse, no pretendan cambiarlo, no se alcen voces críticas, no promuevan siquiera vías de mejora. Esta aceptación tan plena de la situación es sorprendente y difícilmente explicable. No se trata aquí de ningún alegato a la rebelión, pero resulta curioso el rechazo frontal que se generó contra el servicio militar, con una incidencia menor y, en cualquier caso, más limitada en el tiempo, y ninguno - en cambio- frente a este mundo laboral que se ha creado y cuyas consecuencias son mucho mayores en todos los sentidos. Es como si este colectivo tomase una forma extrema de riesgo: grandes cantidades de gente joven apuestan a que ellos serán uno de los pocos elegidos; esta actitud se da en los mercados que se ha dado en llamar eel-ganador-se-lo-lleva-todom. Para la formación de estos mercados, la flexibilidad es un elemento esencial que acentúa la desigualdad.

En cualquier caso, y así las cosas, todas las empresas de todos los sectores llegan a una misma conclusión: sobran trabajadores y es necesario llevar a cabo un ajuste. Es tal la frecuencia y el tiempo que se viene escuchando esa conclusión, tan diferentes los agentes que la propagan y tan aparentemente convincentes los argumentos esgrimidos (avances tecnológicos, mejoras de la productividad, competencia internacional de países que no tienen apenas prestaciones sociales, etc...) que la sociedad lo ha asumido como acervo adquirido, de forma casi natural, como las canciones populares. De este modo, aunque estos argumentos constituyan verdaderas amenazas, es necesario aprender a vivir con ellos y, con tal de que no afecten a uno mismo, se es capaz de dejar que se materialicen y extiendan a toda la sociedad. Se justifican, en definitiva, muchas agresiones. 
Pero es que, además, en muchas ocasiones ese exceso de personal (tan manido en la mayoría de las negociaciones de cualquier tipo) no responde tanto a consideraciones técnicas de obsolescencia o de desfase, como a que su plena utilización e inserción, en esa supuesta empresa camino de transformarse, exige mucha dedicación por parte de la propia empresa y jefes; dedicación que, desde luego, éstos no están dispuestos a conceder porque es a costa de ocuparse menos de sus prioridades laborales (como son el propio interés, despachar con el inmediato superior y, en definitiva, salir en todas las fotos en color -en las blanco y negro, ni en una-). Nunca los reconocimientos, según ellos, vienen de los esfuerzos dedicados a compañeros de posiciones inferiores. Cuantos más miembros haya esperando el cambio en el colectivo, más evidente será la escasa atención que ese colectivo recibe y, por tanto, más posibilidades existirán de que al jefe inmediato se le acuse de mal gestor; ergo, sobran.

De nuevo, hay que especificar que no se pretende que el lugar de trabajo sea una escuela o un centro de asistencia social, sino advertir que no debe permitirse que desaparezca la dimensión social del trabajo. ¿De qué servirá una sociedad, o un mundo, con empresas rentables, con plantillas ajustadas, con prestaciones sociales mínimas, sin déficit público y una posición exterior competitiva, si el desempleo es muy grande -0 , si fuere pequeño, con una renta muy mal distribuida - o si la gente no tiene otra esperanza que continuar en trabajos de subsistencia y conformarse con el consumo de bienes? ¿Qué pasará con los individuos menos dotados o con los que no desean dedicarse enteramente al mundo del trabajo? Los ejemplos recientes de Tabacalera, Michelin y la banca en general son harto significativos: empresas con elevados beneficios y, sin embargo, practicando tremendos ajustes de personal.

Lo preocupante es la forma en que ha penetrado este tipo de argumentos. Se asume sin ninguna restricción la necesidad de que las empresas emprendan planes de ajuste, incluso de la forma y magnitud de los señalados. No aparecen argumentos que, por lo menos, puedan rebatir esa situación, ya que, a lo peor, no se puede impedir. En el mundo laboral se asiste a declaraciones de sindicatos que hacen enmudecer de estupefacción por lo distantes que aparecen respecto a sus finalidades básicas, todavía vigentes. La flexibilidad del mercado laboral y la congelación salarial, por ejemplo, no sólo no se negocian, sino que son totalmente admitidas.

Un ejemplo de la falta de argumentos alternativos con capacidad de enfrentarse a los que se ofrecen con una vocación globalizadora lo proporciona, de nuevo, el mercado de trabajo. Supongamos un trabajador cuyo rendimiento no es satisfactorio para la empresa y, por tanto, decide des- 
pedirlo. Si la economía en cuestión presenta un mercado laboral muy flexible, donde el coste de despido es muy reducido o, incluso, inexistente, el empresario simplemente le despide. Si, por el contrario, el trabajador tiene derechos de propiedad debido a la existencia de leyes de protección del empleo, la empresa tiene que comprar esos derechos. En ambos casos, se produce un resultado eficiente, pues el trabajador es despedido ya que no es productivo. Sin derechos de propiedad, la empresa obtiene todos los beneficios de la eficiencia extra; con derechos de propiedad, el beneficio es compartido con el trabajador. El nivel de empleo es el mismo; sólo la distribución de las ganancias es diferente. Determinados estudios encuentran que, en la práctica, las leyes de protección de empleo parecen tener poco efecto sobre el nivel de empleo, aunque no sobre su contenido. En efecto, en estos estudios ${ }^{1}$ se concluye que la flexibilidad del mercado laboral estadounidense no es sustancialmente mejor para alcanzar la eficiencia económica. La principal diferencia entre economías más flexibles (Estados Unidos, Reino Unido, Canadá, Nueva Zelanda...) y las menos flexibles (Alemania, España, Francia...) no es en términos de productividad o empleo, exclusivamente, sino en la distribución de la renta. Las economías menos flexibles son más igualitarias y no son, en general, menos productivas. Obviamente, si el empleo y la productividad continúan creciendo como en los últimos meses y Europa fracasa en desarrollar lo que se ha llamado nueva economía, este veredicto debería revisarse. Por supuesto que existen, a su vez, contraargumentos a este desarrollo, pero la cuestión es que aparezcan respuestas alternativas, que exijan a la otra parte argumentos más sofisticados.

En estas circunstancias, la presión sobre los trabajadores de edad intermedia es muy fuerte (aunque cada vez esta edad se reduce más; así, por ejemplo, en un famoso banco de inversiones estadounidense, un empleado de 32 años era el año pasado el más antiguo de su sección de fusiones y adquisiciones de Nueva York). De hecho, las generaciones de los sesenta años y buena parte de los cincuenta han desaparecido o están desapareciendo del mercado laboral en los países europeos (véase cuadro 1).

1 Freeman, R. T., "Singled Peaked versus Diversified Capitalism: The Relation Between Economic Institutions and Outcomes". National Bureau Economic Research. Mass. Marzo 2000. 
CUADRO I

TASA DE EMPLEO MASCULINO CON EDADES COMPRENDIDAS ENTRE 55 Y 64 AÑOS PARA 11 PAÍSES (1971-1977)

\begin{tabular}{|c|c|c|c|c|c|c|c|c|c|}
\hline PAISS & 1980 & 1985 & 1987 & 1989 & 1991 | - l & 1993 & 1995 & 1996 & 1997 \\
\hline Estados Unidos & 68,8 & 64,4 & 64,5 & 64,3 & 63,9 & 63,1 & 63,6 & 64,7 & 65,5 \\
\hline Francia ...................... & 65,3 & 46,7 & 43,9 & 43,3 & 42,0 & 40,3 & 38,7 & 38,6 & 38,4 \\
\hline Alemania $^{*}$... & 64,1 & 53,6 & 54,1 & 51,7 & 49,9 & 48,0 & 48,0 & 48,0 & 47,3 \\
\hline Países Bajos .. & 61,0 & 44,2 & 44,7 & 44,2 & 41,8 & 40,5 & 41,0 & 40,7 & 43,0 \\
\hline Suecia ................. & 77,5 & 73,2 & 73,4 & 73,9 & 73,7 & 65,9 & 64,4 & 66,0 & 64,7 \\
\hline Reino Unido. & 73,9 & 59,4 & 58,1 & 61,6 & 61,5 & 55,9 & 56,0 & 57,0 & 58,6 \\
\hline Irlanda ........... & 72,2 & 64,7 & 62,7 & 59,9 & 60,2 & 59,1 & 59,1 & 58,7 & 57,8 \\
\hline Portugal . & 74,8 & 64,9 & 62,1 & 63,9 & 66,5 & 59,9 & 59,1 & 58,5 & 58,2 \\
\hline España ... & 71,5 & 59,1 & 57,0 & 56,7 & 56,2 & 51,6 & 48,0 & 49,9 & 50,5 \\
\hline Canadá ... & 72,7 & 64,3 & 61,9 & 61,9 & 57,3 & 55,0 & 54,0 & 54,7 & 56,1 \\
\hline Japón ............................ & 82,2 & 78,9 & 78,2 & 79,2 & 82,0 & 82,1 & 80,8 & 80,6 & 80,9 \\
\hline
\end{tabular}

* Alemania reunificada a partir de 1991.

Fuente: OCDE - Estadísticas de la población activa y cálculos propios.

En Francia, por ejemplo, la tasa de empleo masculino entre 55-64 años ha pasado de representar un $46,7 \%$ en 1980 a un $38,4 \%$ en 1997. En España, pasó de un $71,5 \%$ a un $50,5 \%$ en el mismo periodo. En Estados Unidos se ha mantenido, en cambio, igual (alrededor de un 64,5\% entre ambas fechas), cuando se podía suponer que al ser éste el país donde el avance tecnológico es mayor y está más extendido, la participación de los mayores en el mercado laboral hubiera registrado la mayor caída.

Según la Central de Balance del Banco de España, en este país se crean todos los años, aproximadamente, 100.000 empresas y se destruyen unas 40.000. Las empresas que sobreviven, al menos temporalmente, tienen una plantilla de seis personas, lo que explica, grosso modo, la creación de empleo de 350.000 personas. Por su parte, las grandes corporaciones están ajustando plantillas de una forma drástica e intensa. El problema es que no existe apenas trasvase entre esos dos bloques de empresas; es decir, los trabajadores despedidos de estas grandes corporaciones no son absorbidos por las pequeñas que se crean, puesto que se dirigen al sector más joven del mercado laboral.

Como se ha señalado anteriormente, se esgrime, entre otros argumentos, que los trabajadores mayores tienen modos de pensar inflexibles y son reacios al riesgo, además de carecer de la energía física necesaria 
para hacer frente a las exigencias de la vida en un trabajo flexible. La flexibilidad es sinónimo de juventud; la rigidez, de vejez. De aquí surge una de las diferencias más importantes entre el funcionamiento del mercado laboral de las economías norteamericana y europea. No es tanto la flexibilidad, ni tan siquiera la movilidad de la fuerza de trabajo (aunque son muy importantes), sino la respuesta que el mercado da a esta presión de los trabajadores jóvenes. Se trata de adecuar a los nuevos trabajadores con las características anteriormente señaladas, sin olvidar a los más veteranos.

La respuesta (al menos inicial) de Europa y de España a este estado de cosas ha sido la jubilación anticipada de los trabajadores antiguos en muchos sectores. Pocas ideas empresariales han prendido tan rápidamente y de forma tan homogénea como la de rejuvenecer plantillas. En muchas ocasiones parece como si la razón fuera meramente estética, ó una imposibilidad probada de que empleados de edades dispares puedan convivir en la misma empresa. En principio, la jubilación anticipada parece rechazable porque deteriora a la persona afectada y representa una amenaza a la viabilidad del sistema de pensiones. Sin embargo, si la alternativa es seguir en el puesto de trabajo pero apartado de toda actividad de la empresa, sin posibilidad de formarse y, en definitiva, deteriorándose en todos los aspectos, como ocurriría con los funcionarios si se materializaran las insinuaciones del partido en el poder sobre incentivos para jubilarse tardíamente, es preferible la jubilación anticipada e intentar luego desarrollar una actividad personal fuera de esos mercados de trabajo, a semejanza de lo observado en Estados Unidos.

En efecto, mientras que en Europa, como se ha señalado, la respuesta inicial y, por ahora, única ha sido la pre-jubilación, en Estados Unidos lit respuesta engloba lo que se podría denominar la segunda oportunidad. Dentro de las mismas amenazas que asolan los mercados laborales, existe todo un conjunto de circunstancias que permiten adoptar las decisiones necesarias para empezar una nueva forma de desarrollo profesional - $\mathrm{e}$ incluso vital - una vez agotada su anterior etapa. Esto sería uno de los factores que podría explicar por qué en Estados Unidos la tasa de participación en el mercado de trabajo de las personas comprendidas entre 55-65 no ha variado desde 1980; es decir, durante el periodo del mayor cambio tecnológico jamás conocido en la historia.

Algún proceso de sustitución de personas se tiene que estar dando desde sectores con una rápida innovación tecnológica y, por lo tanto, con capacidad de acoger a las nuevas generaciones y de expulsar a las antiguas hacia otros donde el avance tecnológico es menor y más limitado, y que absorbe a esos expulsados del primer sector que, para el segundo, 
son personas muy preparadas. Por supuesto, este trasvase no significa decisiones de "tirarse al monte" a la desesperada: parado, y aceptando casi cualquier cosa en cualquier lugar.

Facilitar este aterrizaje suave de aquellas generaciones desplazadas por otras más jóvenes y mejor preparadas en sectores profesionales tecnológicamente sofisticados hacia otros sectores menos exigentes tecnológicamente, o que presentan un mayor periodo de maduración de su tecnología, constituye el verdadero reto social a que se enfrenta la Unión Europea, sobre todo si se considera el envejecimiento de su población y que, a lo mejor, las nuevas tecnologías de la información y de la comunicación son ahorradoras de capital. 